Ann. Génét. Sél. anim., I980, 12 (4), 343-36r.

\title{
Gène Cou nu, performances de ponte et efficacité alimentaire selon la température chez la poule
}

\author{
A. BORDAS, L. E. MONNET $\left({ }^{*}\right)$ et P. MÉRAT \\ avec la collaboration technique de M. DUMORTIER \\ Laboratoire de Génétique Factorielle, \\ Centre National de Recherches Zootechniques, I.N.R.A., \\ 78350 Jouy-en-Josas, France
}

\begin{abstract}
Résumé
Des poules de trois génotypes $\mathrm{NaNa}$ (homozygotes " cou nu "), $\mathrm{Nana}^{+}$(hétérozygotes " cou nu ") et $n a^{+} n a^{+}$(plumage normal), écloses à partir des mêmes parents, ont été distribuées dans deux groupes provenant chacun d'une éclosion distincte : " témoin " (gardé à une température modérée, avec des fluctuations suivant les variations climatiques) et " chauffé " (3 I ${ }^{\circ} \mathrm{C}$ constamment de 4 à 39 semaines d'âge). Les performances de ponte ont été mesurées de 27 à 39 semaines d'âge, ainsi que la consommation alimentaire. Dans le lot témoin, les femelles homozygotes " cou nu " avaient un poids corporel adulte considérablement inférieur (d'environ $300 \mathrm{~g}$ ) à celui des poules à plumage normal, quoique leur consommation alimentaire par 28 jours soit supérieure d'environ $400 \mathrm{~g}$ et leur poids moyen d'œufs de $2,5 \mathrm{~g}$. Elles avaient davantage d'œufs cassés; leurs œufs contenaient approximativement la même quantité de jaune mais davantage d'albumen, la hauteur de ce dernier étant moindre que pour les poules normales. Il y avait plus d'œufs mous (sans coquilles) chez les poules $\mathrm{NaNa}$. Les hétérozygotes étaient en général intermédiaires pour ces caractères, mais elles étaient plus proches du génotype $n a^{+} n a^{+}$pour la consommation d'aliment, le poids moyen des œufs et le rapport jaune/albumen, et plus voisines des poules $N a N a$ pour l'épaisseur de l'albumen.

Dans le lot chauffé, les poules homozygotes "cou nu » avaient un poids corpor $\epsilon 1$ légèrement (mais non significativement) plus élevé que les femelles homozygotes normales; elles consommaient $33^{8} \mathrm{~g}$ de plus de nourriture par 28 jours; le poids moyen de leurs œufs était de $4,5 \mathrm{~g}$ supérieur à celui des femelles $n a^{+} n a^{+}$, le jaune et l'albumen étant tous deux plus lourds. Comme dans le lot témoin, la hauteur de l'albumen était moindre pour les poules $\mathrm{NaNa}$. Les hétérozygotes étaient intermédiaires, mais plus proches des individus $\mathrm{NaNa}$ pour le poids moyen des œufs et la consistance de l'albumen. Le nombre d'œufs était légèrement plus élevé pour les oiseaux "cou nu" dans le lot chauffé, quoique non significativement.

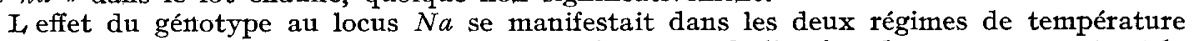
ambiante pour la consommation d'aliment, le poids moyen de l'œuf et de ses composants et la hauteur de l'albumen; d'autre part, il y avait une interaction génotype $\times$ milieu significative ou hautement significative pour le poids corporel adulte, la consommation alimentaire " résiduelle " (corrigée pour le poids corporel et la masse d'œufs pondus), le poids moyen des aufs et $d u$ jaune, le rapport jaune/albumen.
\end{abstract}

(*) Adresse actuelle : E.N.S.A., 08 B.P. 35, Abidjan, Côte-d'Ivoire. 


\section{Introduction}

De très nombreux travaux mettent en évidence 1'effet dépressif plus ou moins accentué d'une température élevée sur les performances des poules pondeuses (nombre d'œufs, poids moyen des œufs, épaisseur et solidité des coquilles), ainsi que sur la consommation alimentaire et le poids corporel, l'efficacité alimentaire étant par contre généralement améliorée. On peut par exemple se référer aux revues de Payne (I966), Smith et Oliver (I97I), Simth (I973, I974), Emmans (1974).

Il existe, d'autre part, des différences génétiques đe réponse des poules adultes à une température élevée en ce qui concerne leurs performances. Des différences entre races ou lignées ont été trouvées par divers auteurs pour des paramètres physiologiques ou zootechniques, production et caractères des œufs, poids corporel, consommation alimentaire (HILIERMAN et WILSON, I954; HUSTON et al., I957; CAmpos et al., I960; CLARK et AMrN, I965; Ahmad et al., I967; DoRminey, ig68; Chima, I975; Petersen et al., I976; Petersen et Horst, i978). Pour la viabilité en stress hyperthermique, des différences raciales ont également été enregistrées (WILsON et al., I972; EMERSON, I975). Plusieurs de ces auteurs montrent que les races de petite taille supportent mieux les températures élevées que les races lourdes. Certaines races locales des régions chaudes, comme la race Bédouine au Moyen-Orient, paraissent d'autre part être dotées de caractéristiques physiologiques particulières leur permettant de s'adapter aux températures excessivement élevées (MARDER et al., I974, cités par ARAD et al., I975).

Quant au rôle de gènes particuliers dans la thermotolérance des poules adultes, il a été l'objet de peu de recherches; MERAT et al. (I974), Horst et PeTERSEN (I979), trouvent à cet égard un avantage associé au gène de nanisme lié au sexe $d w$. Ces résultats vont dans le sens de la suggestion de SELVARAJAH (I970) et de GUILLAUME (I976) selon lesquels les poules naines présentent un intérêt potentiel pour les pays tropicaux.

Le gène $N a(\operatorname{cou} n u)$, qui limite l'extension du plumage (HUTT, I949) avec une dominance incomplète (CRAWFORD, I976; ScOTT et CRAWFORD, I977), paraît mériter a priori d'être étudié quant à ses effets sur les performances, en fonction de la température ambiante. Chez le jeune, un effet favorable sur la croissance pondérale jusqu'à ro semaines a été trouvé associé à ce gène lorsque la température est maintenue au-dessus de $30{ }^{\circ} \mathrm{C}$ (Bordas et al., I978; MONNET et al., I979). En réponse à un stress thermique, SMITH et LEE (I977) observent moins de mortalité pour des poussins hétérozygotes $\mathrm{Nana}^{+}$que pour ceux de génotype $n a^{+} n a^{+}$. Par contre, le gène $N a$ a été très peu étudié quant à ses effets chez la poule adulte en relation avec la température. MERAT et al. (I974) n'ont pas mis en évidence une différence de réponse à une température élevée entre 1'hétérozygote et 1'homozygote récessif quant aux performances de ponte, dans une expérience préliminaire en effectifs limités.

L'objet du présent travail est, par suite, de comparer la ponte, les caractéristiques des œufs et l'efficacité alimentaire de poules de trois génotypes $\mathrm{NaNa}$, $N a n a^{+}$et $n a^{+} n a^{+}$, selon la température ambiante, modérée ou chaude. 


\section{Matériel et méthodes}

\section{I. - Matériel animal et conditions expérimentales}

Les animaux utilisés et les conditions expérimentales jusqu'à l'âge de ro semaines ont été décrits précédemment (MonNET et al., I979). Nous en rappellerons ce qui est nécessaire à la compréhension du présent travail.

Les poussins expérimentaux sont issus de parents tous deux hétérozygotes $\mathrm{Nana}^{+}$( 9 pères au total et 4 à 8 mères par père). Ces parents, élevés à Jouy-en-

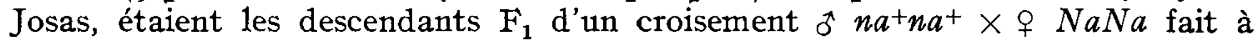
l'élevage de Las Costes comme dans une précédente expérience (BORDAS et al., I978). Les poussins provenaient de deux éclosions pedigree espacées de $2 \mathrm{I}$ jours, la première datant du 26 septembre I978. A l'éclosion, le sexe et le génotype $\left(\mathrm{NaNa}, \mathrm{Nana}^{+}\right.$ou $\left.n a^{+} n a^{+}\right)$étaient déterminés. La première éclosion devait fournir, pendant la période expérimentale ultérieure, le lot "témoin ", la seconde éclosion donnant le lot "chauffé ", dont les conditions d'élevage sont données ci-dessous.

Les deux lots, comprenant chacun 55 poulettes gardées par génotype après 2 semaines d'âge, étaient élevés au sol, chacun dans une cellule de poussinière, jusqu'à 1'âge de $\mathrm{I} 8$ semaines. A cet âge, après élimination au hasard dans certaines familles, 40 poulettes par génotype et lot étaient mises en cages individuelles, dans un bâtiment distinct pour chaque lot, jusqu'à la fin de l'expérience.

Le lot " témoin " et le lot " chauffé " recevaient constamment, de l'éclosion à la fin de l'expérience, I4 heures de lumière et ro heures d'obscurité par jour. L'eau et l'aliment étaient distribués ad libitum de façon identique pour lesdeux lots. $\mathrm{L}_{\mathrm{a}}$ ration, donnée sous forme de farine tout au long de l'expérience, était à I $8 \mathrm{p}$. Ioo de protéines totales et $2900 \mathrm{kcal} / \mathrm{kg}$ (I I, $8 \mathrm{~mJ}$ ) d'énergie métabolisable de 0 à Io semaines, I 7 p. Ioo de protéines et $2850 \mathrm{kcal} / \mathrm{kg}$ d'E.M. de Io à I 8 semaines, enfin $\mathrm{I} 6 \mathrm{p}$. Ioo de protéines et environ $2600 \mathrm{kcal} / \mathrm{kg}$ d'E.M. à partir de I 8 semaines, avec une transition d'une semaine.

A l'âge de 27 semaines pour chaque lot, après que la totalité des poulettes soit entrée en ponte, commençait la phase expérimentale. Elle comportait trois périodes consécutives de 28 jours et débutait le 22 mars 1979 en lot témoin et le II avril 1979 en lot chauffé.

A part la date d'éclosion décalée, les conditions d'élevage des deux lots, par suite de contraintes matérielles, comportaient quelques différences que nous considérons comme mineures : jusqu'à $I 8$ semaines d'âge, le lot témoin recevait la lumière du jour supplémentée par un éclairage électrique, le lot chauffé recevait seulement un éclairage artificiel. Après I 8 semaines en cages, le lot témoin était placé à l'étage inférieur d'une batterie de trois étages, le lot chauffé occupait, dans un local semblable, une batterie à un seul étage. Quant à la différence essentielle entre les deux lots, elle résidait dans la température ambiante réalisée. A I jour d'âge, les poussins destinés au lot témoin recevaient une température initiale sous éleveuse voisine de $35^{\circ} \mathrm{C}$, diminuant graduellement, puis à partir de 4 semaines et jusqu'à la fin, 1a température suivait les fluctuations ambiantes, un chauffage d'appoint empêchant seulement qu'elle ne descende en-dessous d'environ Io ${ }^{\circ} \mathrm{C}$ lors des journées les plus froides. Pour le lot chauffé, le régime de température était identique à celui du lot témoin durant les 2 premières semaines, puis la température était maintenue en permanence au voisinage de $3{ }^{\circ} \mathrm{C}$ jusqu'à la fin de l'expérience par un chauffage avec thermostat. Le tableau I 
indique, pour les trois phases successives o-Io semaines, I0-27 semaines et 2739 semaines, les valeurs extrêmes obtenues pour les maxima et minima journaliers dans chaque période en lot témoin d'une part, en lot chauffé d'autre part. Ces indications suffisent à montrer qu'une différence considérable de température ambiante a toujours été maintenue entre les deux lots. Les fluctuations du lot chauffé, sans être négligeables, sont beaucoup plus limitées que celles du lot témoin. Ce dernier, en particulier, a subi un net refroidissement entre ro et 27 semaines d'âge, suivi d'un relatif réchauffement, reflétant les conditions saisonnières. Le degré hygrométrique n'a pas été contrôlé de façon précise. Il se situait dans une zone relativement basse, généralement en dessous de $50 \mathrm{p}$. Ioo.

TABLEAU I

Valeurs extrêmes pour les maxima et minima journaliers de température durant trois tranches d'âge

Extreme values for daily maxima and minima of temperature during three age periods

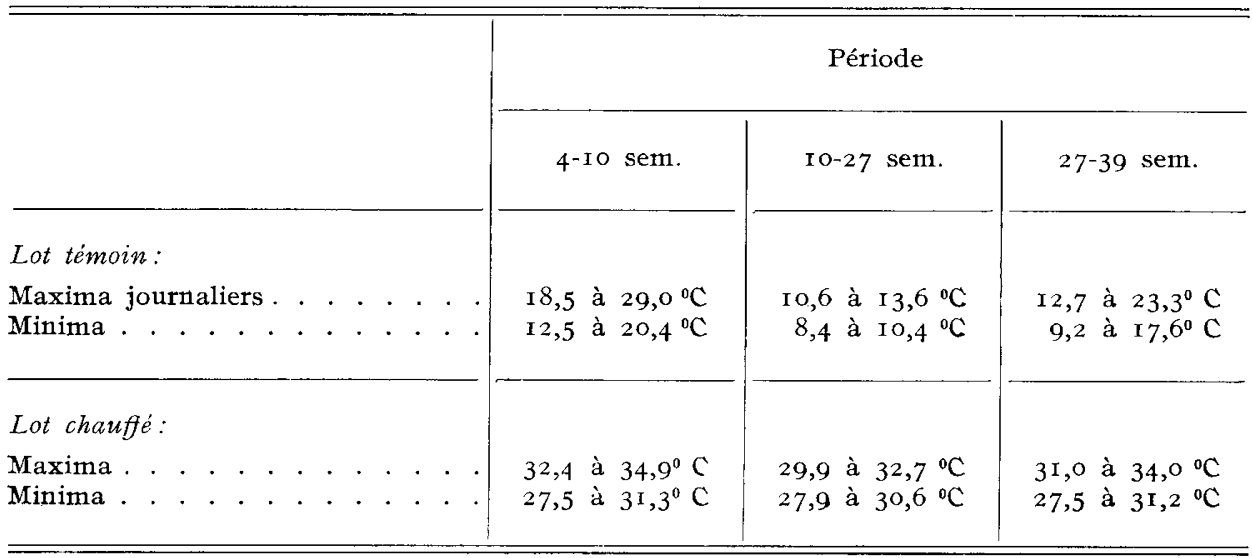

2. - Critères mesurés ou calculés

Précocité sexuelle

L'âge au premier œuf (en jours), survenu toujours après la mise en cages, mesure la précocité sexuelle.

Mesure de production et d'efficacité alimentaire sur 3 périodes de 28 jours

Par animal et par période sont enregistrés la consommation alimentaire $(\mathrm{O})$, le poids corporel $(\mathrm{P})$, moyenne des pesées en début et fin de période, sa variation $(\Delta \mathrm{P})$ entre le début et la fin de cette période $\left({ }^{1}\right)$, le poids total d'œufs pondus (E).

(1) Pesées le matin sur animaux à jeun depuis la veille au soir (I 7 heures) et sans tenir compte du moment d'une oviposition par rapport à la pesée. 
Seule la valeur moyenne des trois périodes, pour chaque individu et chaque variable, est utilisée ici. Une consommation théorique $T$ est ensuite estimée par oiseau en fonction de ses valeurs individuelles pour les variables $\mathrm{P}, \Delta \mathrm{P}$ et $\mathrm{E}$, suivant une équation de régression multiple :

$$
\mathrm{T}=a \mathrm{P}^{\alpha}+b \Delta \mathrm{P}+c \mathrm{E}
$$

Cette équation est du type décrit par BYERLY (I94I) et d'autres auteurs, par exemple LEESON et al. (I973), Gous et al. (I978), McDonalD (I978). Nous avons retenu pour $\alpha$ la valeur 0,5 proche de l'optimum donnant la variance minimum pour les écarts à la régression. Une équation de régression a été établie par lot, après avoir vérifié que, dans chaque lot, les coefficients $a, b, c$ n'étaient pas significativement différents suivant le génotype. Les équations n'étant pas non plus différentes entre lots, une équation commune a finalement été utilisée. Elle est la suivante :

$$
\mathrm{T}=95,8 \mathrm{P}^{0,5}+2, \mathrm{I} \Delta \mathrm{P}+\mathrm{I}, \mathrm{I} \mathrm{E}-2302
$$

La différence $\mathrm{R}=\mathrm{O}-\mathrm{T}$ entre consommation observée et théorique pour chaque poule sera appelée consommation " résiduelle ${ }_{2}$.

Autres variables de ponte et caractéristiques des cufs

Les autres variables retenues ici sont :

- le nombre d'œufs pondus du premier œuf à la $39^{\mathbf{e}}$ semaine d'âge;

- le poids moyen des œufs, sur la ponte de 2 semaines dans la dernière période de 28 jours;

- la hauteur de l'albumen de l'œuf cassé, sur 2 œufs par poule dans la dernière période;

- l'épaisseur de la coquille séchée, membrane comprise, sur 2 œufs par poule dans la dernière période;

- le pourcentage d'œufs cassés ou fêlés sur l'ensemble des trois périodes de 28 jours;

- le poids des composants de l'œuf, jaune, albumen et coquille, et le rapport du poids du jaune au poids de l'albumen, sur I œuf par poule au cours de la dernière période.

D'autre part, l'évolution du nombre des œufs pondus et de leur poids moyen au cours des trois périodes successives de contrôle de 28 jours a été comparée pour les 3 génotypes dans chaque lot.

\section{3. - Analyse statistique des données}

Sur chaque caractère mentionné est faite à l'intérieur de chaque lot une analyse de variance à 2 facteurs, génotype et famille de père. D'autre part, sur ces mêmes variables, est appliquée une analyse de variance à 3 facteurs, génotype, famille de père et environnement, pour les deux lots réunis.

Lorsque 1'analyse de variance indique un effet significatif du génotype, les génotypes sont comparés deux à deux par la méthode du $t$ corrigé. 


\section{Résultats}

Pour les poules du lot témoin, le tableau 2 donne les valeurs moyennes par caractère et par génotype; le tableau 3 présente les analyses de variance à 2 facteurs (génotype et famille de père) correspondantes. Les tableaux 4 et 5 indiquent respectivement, pour le nombre d'œufs et le poids des œufs, l'évolution de la valeur moyenne au cours des trois périodes de contrôle de 4 semaines chacune et l'analyse de variance selon le génotype et la période.

Pour les poules du lot chauffé, les résultats similaires sont présentés respectivement dans les tableaux $6,7,8$ et 9 .

Le tableau ro donne les moyennes des variables étudiées, tous génotypes réunis, pour le lot témoin d'une part, le lot chauffé d'autre part. Le tableau II indique la signification des analyses de variance à 3 voies (environnement, génotype, famille de père).

\section{Discussion et conclusions}

\section{I. - Lot témoin}

Comme 1'indiquent les tableaux 2 et 3 , la précocité sexuelle, de même que le nombre d'œufs pondus depuis le premier œuf jusqu'à la fin du contrôle (39 semaines), ne diffèrent pas significativement entre génotypes au locus $N a$. Il en est de même de la masse d'œufs pondus (E) et de la variation du poids corporel $(\Delta \mathrm{P})$ par 28 jours entre les âges de 27 et 39 semaines. Par contre, le poids corporel moyen dans cette période diffère significativement entre les 3 génotypes (plus de $300 \mathrm{~g}$, soit environ II p. Ioo entre les 2 homozygotes). Ceci correspond à un accroissement de poids inférieur pour les poulettes des 2 génotypes " cou $n u$ " entre ro et 27 semaines, et plus spécialement entre ro et I 8 semaines (MONNET et al., I980). D'autre part, la consommation alimentaire globale (O) est significativement supérieure chez le mutant $\mathrm{NaNa}$ comparé à $\mathrm{Nana}^{+}$et $n a^{+} n a^{+}$: de 7 et 9 p. Ioo respectivement, soit I0,4 et $13,7 \mathrm{~g}$ d'aliment par individu et par jour. Ceci va en sens inverse de la différence de poids corporel à l'âge adulte et reflète un besoin d'entretien différent à poids égal. La variable $\mathrm{R}$ (consommation " résiduelle ") est très significativement supérieure pour le génotype $\mathrm{NaNa}$ comparé aux autres génotypes, mettant en évidence une efficacité alimentaire médiocre du premier; 1'hétérozygote est intermédiaire et plus proche de l'homozygote normal.

L'examen de la ponte et du poids moyen des oufs par périodes (tab1. 4 et 5) montre respectivement une diminution significative de la première et une augmentation $\mathrm{du}$ second au cours du temps dans l'ensemble des génotypes. Dans les 2 cas, il n'y a pas d'interaction entre génotype au locus $N a$ et période.

Les tableaux 2,3 et 5 mettent en évidence une influence hautement significative du gène "cou $n u$ " sur le poids moyen des œufs : l'individu $N a N a$ a, en moyenne, le poids d'œuf le plus élevé, sa supériorité par rapport à l'hétérozygote et à l'homozygote récessif étant respectivement 2,3 et $2,5 \mathrm{~g}$. Cette supériorité se manifeste malgré le poids corporel moyen nettement inférieur pour les "cou nu» homozygotes et le fait que poids corporel et poids de l'œuf soient en corrélation 
TABLEAU 2

Paramètres de production, d'efficacité alimentaire et caractéristiques des aufs Moyennes - Lot témoin

Parameters concerning egg production, food efficiency and egg traits Means - Control group

Paramètres

Age au I er œuf (j) . . . . . . . . . . Poids moyen (P) entre 27 et 39 sem. (g) Variation de poids $(\Delta \mathrm{P})$ par $28 \mathrm{j}(\mathrm{g})$. Masse d'œufs produite (E) par $28 \mathrm{j}(\mathrm{g})$.

Consommation alimentaire (O) par $28 \mathrm{j}(\mathrm{g})$ Consommation résiduelle (R) par $28 \mathrm{j}(\mathrm{g})$ Nombre total d'œufs (I er œuf - 39 sem.) Poids moyen de l'œuf $(\mathrm{g})$. . . . . . . P. I oo cufs cassés ( 27 à 39 sem.) . . . Poids du jaune $(\mathrm{g})$. . . . . . . . . . Poids du blanc (g) . . . . . . . . . . Poids de coquille $(\mathrm{g})$. . . . . . . . . Épaisseur d'albumen (r/ro mm)... . Epaisseur de coquille (I/I0o mm) . . Rapport jaune/blanc (p. Ioo).

\begin{tabular}{|c|c|c|}
\hline \multicolumn{3}{|c|}{ Génotypes } \\
\hline $\mathrm{NaNa}$ & $\mathrm{Nana}^{+}$ & natna+ \\
\hline I 60,8 & I $63, \mathrm{I}$ & I 58,9 \\
\hline $2599^{a}$ & $2729^{b}$ & $2905^{c}$ \\
\hline Io, 8 & 6,9 & $-5,8$ \\
\hline I 048 & I 073 & I 030 \\
\hline $4263^{a}$ & $3972^{b}$ & $3879^{b}$ \\
\hline $505,6^{a}$ & $77, \mathrm{I}^{\mathrm{b}}$ & $-99,7^{c}$ \\
\hline 76,9 & 79,0 & 79,9 \\
\hline $59, \mathrm{x}^{a}$ & $56,8^{b}$ & $5^{6,6^{b}}$ \\
\hline $23,4^{a}$ & I I, $7^{b}$ & $14,5^{b}$ \\
\hline $\begin{array}{l}16,02 \\
35,00^{a}\end{array}$ & $\begin{array}{l}16,02 \\
33,35^{b}\end{array}$ & $\begin{array}{l}16,00 \\
33,19^{b}\end{array}$ \\
\hline $\begin{array}{c}5,12 \\
5,12\end{array}$ & $\begin{array}{r}33,33 \\
5,03\end{array}$ & $\begin{array}{r}33,190 \\
5,04\end{array}$ \\
\hline $60,6^{a}$ & $62,8^{a}$ & $68, \mathrm{I}^{b}$ \\
\hline 38,8 & 38,9 & 39,4 \\
\hline $45,8^{a}$ & $4^{8}, 3^{b}$ & $4^{8}, 6^{b}$ \\
\hline
\end{tabular}

Les moyennes suivies de lettres différentes sont significativement différentes.

TABLEAU 3

Paramètres de production, d'efficacité alimentaive et caractéristiques des ceufs Analyse de variance - Lot témoin

Parameters concerning egg production, food efficiency and egg traits Variance analysis - Control group

\begin{tabular}{|c|c|c|c|c|}
\hline \multirow{2}{*}{ Paramètres } & \multicolumn{4}{|c|}{ Variances et signification } \\
\hline & $\begin{array}{l}\text { Génotype } \\
(\mathrm{d} .1 .=2)\end{array}$ & $\begin{array}{c}\text { Famille } \\
(\text { d.1. }=8)\end{array}$ & $\begin{array}{l}\text { Interaction } \\
(\mathrm{d} .1 .=\mathrm{I} 6)\end{array}$ & Résiduelle \\
\hline Age au I $^{\mathrm{er}}$ œuf . . . & 80 & I38 & $4 \mathrm{I}$ & $47(83)$ \\
\hline Poids moyen $(\mathrm{P})$ & $963945(* * *)$ & $400580(* * *)$ & 67 I56 & $70334(83)$ \\
\hline Variation de poids $(\Delta \mathrm{P})$ & $25 \mathrm{I} 4$ & I 375 & 2765 & $2783(83)$ \\
\hline Masse d'œufs (E) . . . . & I 56 Io & 30016 & 32894 & $38270(83)$ \\
\hline $\begin{array}{l}\text { Consommation alimentaire } \\
\text { (O) . . . }\end{array}$ & I $097523(* * *)$ & I $033577(* * *)$ & IOI 545 & I64966 (83) \\
\hline $\begin{array}{l}\text { Consommation résiduelle } \\
\text { (R). } . . \cdot \cdot \cdot \cdot \cdot \cdot .\end{array}$ & $2984 \operatorname{IIg}(* * *)$ & i $66065\left(^{*}\right)$ & 59403 & 6604 I $\quad(83)$ \\
\hline Nombre d'œufs . . . . . & 73 & I 78 & 2 II & I $85(83)$ \\
\hline Poids moyen des œufs. . & $62,2 \mathrm{I}(* *)$ & $29,27\left(^{*}\right)$ & 6,08 & I $3,07(8 \mathrm{I})$ \\
\hline P. Ioo œufs cassés . . . & I 234,63 & 749,45 & $212,4^{\circ}$ & $42 \mathrm{I}, \mathrm{I} 8$ \\
\hline Poids jaune... . . . & 0,14 & 3,09 & $\mathrm{I}, 24$ & I, $89(80)$ \\
\hline Poids albumen. . . . . . & $33,4^{8}(*)$ & $30,05(* * *)$ & 4,76 & $7,90(80)$ \\
\hline Poids coquille. . . . . . & 0,25 & $0,62(* *)$ & $0,40(*)$ & $0,20(80)$ \\
\hline Épaisseur albumen. . . . & $49 I(* *)$ & $352(* * *)$ & I 73 & $86(8 I)$ \\
\hline Épaisseur coquille. . . & $\mathrm{I}, 7$ & $10,4 \quad(*)$ & 1,9 & $4,9 \quad(8 \mathrm{I})$ \\
\hline Rapport jaune/blanc. . . & $64,12(*)$ & $43,09(*)$ & 12,65 & $16,70(80)$ \\
\hline
\end{tabular}

Entre parenthèses ()$=d .1$.

$(*),(* *),(* * *)=$ significatif respectivement au seuil 5 , I et $0, \mathbf{I}$ p. Ioo. 


\section{TABLEAU 4}

Evolution de la ponte en fonction du génotype et de la période : Lot témoin Evolution of egg production according to genotype and period : Control group

Nombre d'oufs par individu

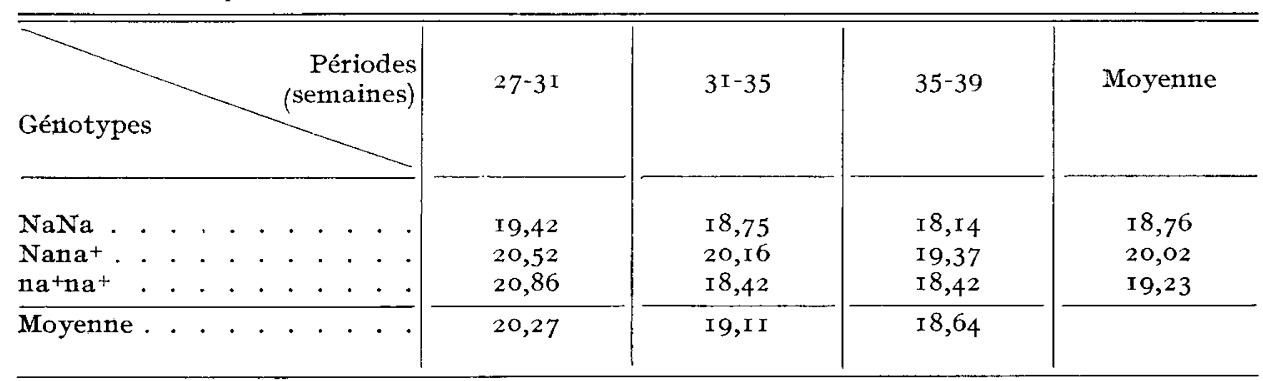

Analyse de variance

\begin{tabular}{|c|c|c|c|c|c|c|c|c|c|c|c|c|}
\hline Sou & ce & de & & varia & tio & & & & & Variance & $\mathrm{d} .1$ & $\mathbf{F}$ \\
\hline $\begin{array}{l}\text { Génotype . } \\
\text { Période . } \\
\text { Interaction. } \\
\text { Résiduelle. }\end{array}$ & $\begin{array}{ll}\cdot & . \\
\cdot & . \\
\cdot & . \\
. & .\end{array}$ & $\begin{array}{ll}\cdot & . \\
\cdot & . \\
\cdot & . \\
\cdot & .\end{array}$ & $\begin{array}{ll}\cdot & \cdot \\
\cdot & \cdot \\
\cdot & \cdot \\
\cdot & \cdot\end{array}$ & $\begin{array}{ll}\cdot & \cdot \\
\cdot & \cdot \\
\cdot & \cdot \\
\cdot & \cdot\end{array}$ & $\begin{array}{l}\cdot \\
\cdot \\
\cdot \\
\cdot\end{array}$ & $\begin{array}{l}\cdot \\
\cdot \\
\cdot \\
\cdot\end{array}$ & $\cdot$ & $\begin{array}{l}\cdot \\
\cdot \\
\cdot \\
\cdot\end{array}$ & $\begin{array}{ll}\cdot & \cdot \\
\cdot & \cdot \\
\cdot & \cdot \\
\cdot & \cdot\end{array}$ & $\begin{array}{l}44,42 \\
77, \text { I } 2 \\
\text { I I }, 83 \\
\text { I } 6,67\end{array}$ & $\begin{array}{r}2 \\
2 \\
4 \\
32 I\end{array}$ & $\begin{array}{l}2,66 \\
4,62(* *) \\
0,71\end{array}$ \\
\hline
\end{tabular}

TABLEAU 5

Évolution du poids moyen de l'cut en fonction du génotype et de la période : Lot témoin Evolution of mean egg weight according to genotype and period : Control group

Poids moyen de l'ouf

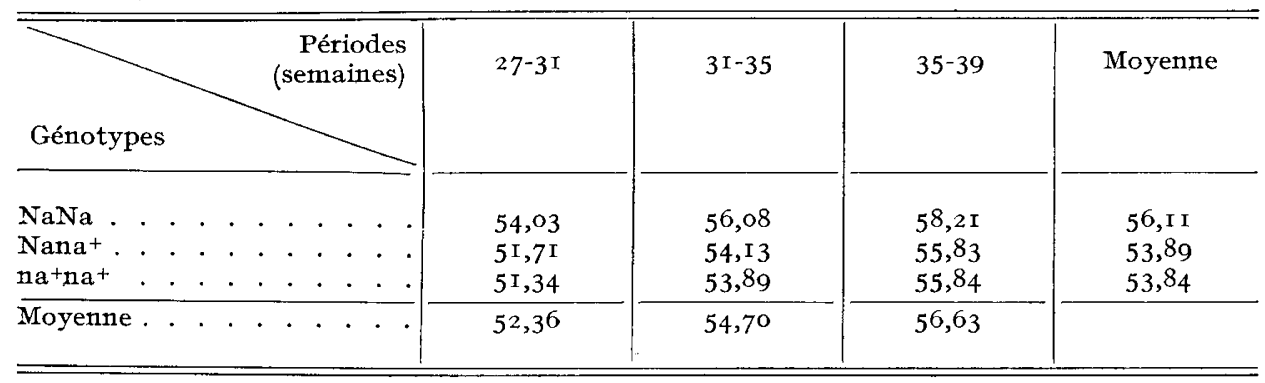

Analyse de variance

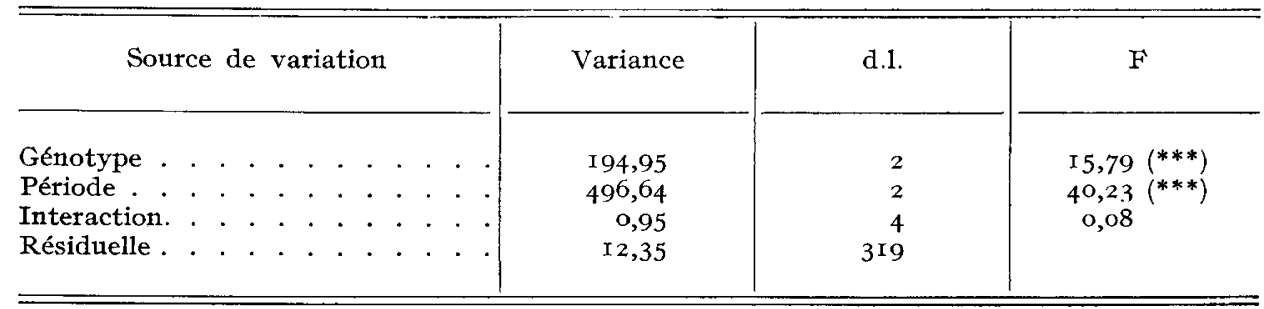




\section{TABLEAU 6}

Paramètres de production, d'efficacité alimentaive et caractéristiques des cufs Moyennes - Lot chaufjé

Parameters concerning egg production, food efficiency and egg traits Means - Heated group

\begin{tabular}{|c|c|c|c|}
\hline \multirow{2}{*}{ Paramètres } & \multicolumn{3}{|c|}{ Génotypes } \\
\hline & $\mathrm{NaNa}$ & Nana ${ }^{+}$ & $\mathrm{na}+\mathrm{na}^{+}$ \\
\hline Age au I $^{\text {er }} œ u f(j)$. & $\mathrm{I} 5^{8, \mathrm{I}}$ & I 57,7 & I 59,0 \\
\hline Poids moyen $(\mathrm{P})$ entre 27 et 39 sem. $(\mathrm{g})$ & 2665 & $26 \mathrm{II}$ & 2525 \\
\hline Variation de poids $(\Delta \mathrm{P})$ par $28 \mathrm{j}(\mathrm{g})$ & $3^{8,4}$ & 28,7 & 22,2 \\
\hline Masse d'œufs (E) par $28 \mathrm{j}(\mathrm{g})$. . . & $95 \mathrm{I}$ & 903 & $86 \mathrm{I}$ \\
\hline Consommation alimentaire $(\mathrm{O})$ par $28 \mathrm{j}(\mathrm{g})$ & $3636^{a}$ & $3488^{b}$ & $329^{c}$ \\
\hline Consommation résiduelle $(\mathrm{R})$ par $28 \mathrm{j}(\mathrm{g})$ & - 132,7 & I 57,3 & $-205,3$ \\
\hline Nombre d'œufs (r er œuf -39 sem.) . & 79,4 & 77,5 & 75,8 \\
\hline Poids moyen œuf $(\mathrm{g})$. & $53,2^{a}$ & $5 \mathrm{I}, 7^{\mathrm{a}}$ & $4^{8}, 7^{b}$ \\
\hline P. Ioo œufs cassés $(27-39$ sem.) . . . & I 2,9 & 14,6 & I 5,4 \\
\hline Poids du jaune $(\mathrm{g}) . . . . . .$. & $\mathrm{I} 6, \mathrm{I}^{a}$ & I $5,3^{b}$ & $14,6^{c}$ \\
\hline Poids du blanc $(\mathrm{g}) . \ldots$ & $31,5^{a}$ & $30,2^{a b}$ & $29,4^{b}$ \\
\hline Poids de coquille $(\mathrm{g})$. . . . . . . . . & 4,67 & 4,62 & 4,37 \\
\hline Épaisseur albumen (I / $0 \mathrm{~mm}) . . .$. & $62,2^{a}$ & $63,7^{a b}$ & $70,5^{b}$ \\
\hline Épaisseur coquille (I/Ioo mm). . . . & 37,8 & 36,9 & 35,6 \\
\hline Rapport jaune/blanc (p. Ioo). . . . . & $5 \mathrm{r}, 3$ & 50,9 & 49,8 \\
\hline
\end{tabular}

Les moyennes suivies de lettres différentes sont significativement différentes.

\section{TABLEAU 7}

Paramètres de production, d'efficacité alimentaive et caractéristiques des oufs Analyse de variance - Lot chauffé

Parameters concerning egg production, food efficiency and egg traits Variance analysis - Heated group

\begin{tabular}{|c|c|c|c|c|}
\hline \multirow[b]{2}{*}{ Paramètres } & \multicolumn{4}{|c|}{ Variances et signification } \\
\hline & $\begin{array}{c}\text { Génotype } \\
\text { (2) }\end{array}$ & $\begin{array}{c}\text { Famille } \\
(8)\end{array}$ & $\begin{array}{l}\text { Interaction } \\
\text { (16) }\end{array}$ & Résiduelle \\
\hline Age au rer œuf $(\mathbf{j}) . \ldots$. & $5^{\circ}$ & I 54 & $8 I$ & $78(8 \mathrm{I})$ \\
\hline Poids moyen $(\mathrm{P}) . .$. & I 80039 & $237389(* *)$ & 42068 & $77454(8 \mathrm{I})$ \\
\hline Variation de poids $(\Delta \mathrm{P})$ & 2 I 77 & $4 \mathrm{I} 77$ & 2806 & $2202(8 I)$ \\
\hline Masse d'œufs (E) . . . . & 69250 & $143401(* *)$ & 42934 & $442 \mathrm{II} \quad(8 \mathrm{I})$ \\
\hline Nombre d'œufs . . . . . & I 47 & $940(* * *)$ & 233 & $238(8 I)$ \\
\hline Poids moyen des œufs . . & $167,07(* * *)$ & I 0,14 & I 5,20 & I 3,42 (77) \\
\hline $\begin{array}{l}\text { P. Ioo oufs cassés } \cdot \dot{.} \cdot \\
\text { Consommation alimentaire }\end{array}$ & 8,91 & $33 x, 36$ & $23^{8}, 20$ & 269,79 (8I) \\
\hline$\underset{\text { Consommation résiduelle }}{(\mathrm{O}) \cdot \cdot \cdot{ }^{\circ}}$ & I I $30806(* * *)$ & $45335 \mathrm{I}(* * *)$ & I07 885 & 977 I I $(8 \mathrm{I})$ \\
\hline (R). . . . . . . . . & 71903 & 42698 & 24300 & $5045^{2}(8 \mathrm{I})$ \\
\hline Poids du jaune. . & $18,23(* * *)$ & $2,4 \mathrm{I}$ & 3,59 & I, I $5(68)$ \\
\hline Poids du blanc. . & $32,76(*)$ & 10,45 & 9,12 & $7,7 \circ(68)$ \\
\hline Poids de coquille. . & $0,8 \mathrm{I}$ & 0,34 & 0,30 & $0,30(68)$ \\
\hline Épaisseur albumeti. . . . & 5 I $5\left(^{*}\right)$ & $368(* * *)$ & IOI & $107(68)$ \\
\hline Épaisseur coquille . . . . & I 8,2 & $2 \mathrm{I}, 3\left(^{*}\right)$ & 5,5 & $8, \mathrm{I} \quad(68)$ \\
\hline Rapport jaune/blanc. . . & $2 \mathrm{I}, 25$ & $47,98(* *)$ & 20,67 & I $5,74(68)$ \\
\hline
\end{tabular}

Entre parentheses ()$=$ d.1.

$(*),\left({ }^{* *}\right),(* * *)=$ significatif respectivement au seuil 5 , I et o, I p. roo. 


\section{TABLEAU 8}

Évolution de la ponte en fonction du génotype et de la période : Lot chauffé Evolution of egg production according to genotype and period : Heated group

Nombre d'cuts

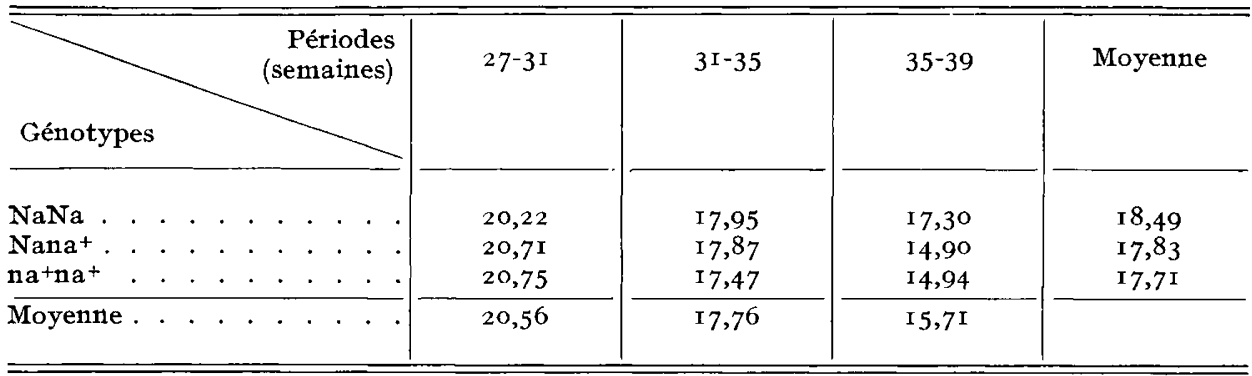

Analyse de variance

\begin{tabular}{|c|c|c|c|c|c|c|c|c|c|c|c|c|}
\hline \multicolumn{3}{|c|}{ Source de } & \multicolumn{7}{|c|}{ variation } & Variance & d.1. & $\mathrm{F}$ \\
\hline $\begin{array}{l}\text { Génotype . } \\
\text { Période. } \\
\text { Interaction. } \\
\text { Résiduelle. }\end{array}$ & $\begin{array}{l}\cdot \\
\cdot \\
\cdot \\
\cdot\end{array}$ & $\begin{array}{l}\cdot \cdot \\
\cdot \quad \cdot \\
\cdot \quad \cdot \\
\cdot \quad \cdot\end{array}$ & $\begin{array}{ll}\cdot & \cdot \\
\cdot & \cdot \\
\cdot & \cdot \\
\cdot & .\end{array}$ & $\begin{array}{l}\cdot \\
\cdot \\
\cdot\end{array}$ & $\begin{array}{l}\cdot \\
\cdot \\
.\end{array}$ & $\begin{array}{l}\cdot \\
\cdot \\
\cdot\end{array}$ & $\begin{array}{l}\cdot \\
\cdot \\
\cdot \\
\cdot\end{array}$ & $\begin{array}{l}\cdot \\
\cdot \\
\cdot \\
\cdot\end{array}$ & $\begin{array}{ll}\cdot & \cdot \\
\cdot & \cdot \\
\cdot & \cdot \\
\cdot & \cdot\end{array}$ & $\begin{array}{r}18,57 \\
635,73 \\
27,29 \\
26,56\end{array}$ & $\begin{array}{r}2 \\
2 \\
4 \\
315\end{array}$ & $\begin{array}{r}0,7 \\
23,9(* * *) \\
1,0\end{array}$ \\
\hline
\end{tabular}

\section{TABLEAU 9}

Évolution du poids moyen de l'œuf en fonction du génotype et de la période : Lot chauffé Evolution of mean egg weight according to genotype and period: Heated group

Poids moyen de l'œuf

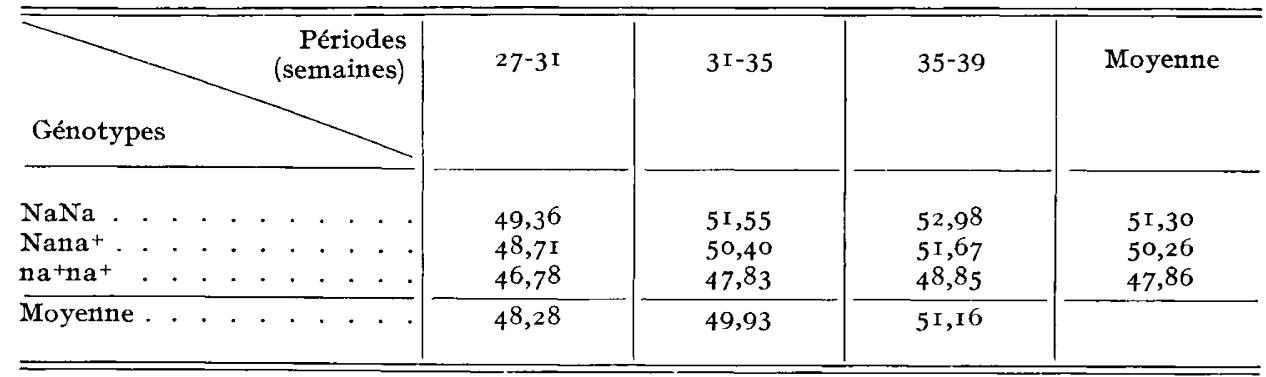

Analyse de variance

\begin{tabular}{|c|c|c|c|c|c|c|c|c|c|c|c|c|}
\hline \multicolumn{4}{|c|}{ Source de } & \multicolumn{6}{|c|}{ variation } & $\begin{array}{l}\text { Variance } \\
316,63\end{array}$ & $\begin{array}{r}\mathrm{d} .1 . \\
2\end{array}$ & $\mathrm{~F}$ \\
\hline $\begin{array}{l}\text { Génotype } \\
\text { Période. } \\
\text { Interaction. } \\
\text { Résiduelle. }\end{array}$ & . & $\begin{array}{l}\cdot \\
\cdot \\
\cdot \\
\cdot\end{array}$ & $\begin{array}{l}\cdot \\
. \\
.\end{array}$ & $\begin{array}{ll}\cdot & \cdot \\
\cdot & \cdot \\
\cdot & \cdot \\
\cdot & \cdot\end{array}$ & $\begin{array}{l}\cdot \\
. \\
.\end{array}$ & $\begin{array}{l}\cdot \\
\cdot \\
\cdot\end{array}$ & $\begin{array}{l}\cdot \\
\cdot \\
\cdot \\
\cdot\end{array}$ & $\begin{array}{l}\cdot \\
\cdot \\
.\end{array}$ & $\begin{array}{ll}\cdot & \cdot \\
\cdot & \cdot \\
\cdot & \cdot \\
\cdot & \cdot\end{array}$ & $\begin{array}{r}316,63 \\
219,39 \\
5,73 \\
13,42\end{array}$ & $\begin{array}{r}2 \\
2 \\
4 \\
310\end{array}$ & $\begin{array}{c}23,6(* * *) \\
16,3(* * *) \\
0,4\end{array}$ \\
\hline
\end{tabular}




\section{TABLEAU IO}

Moyennes par lot, tous génotypes reunis

Means per treatment, genotypes being grouped

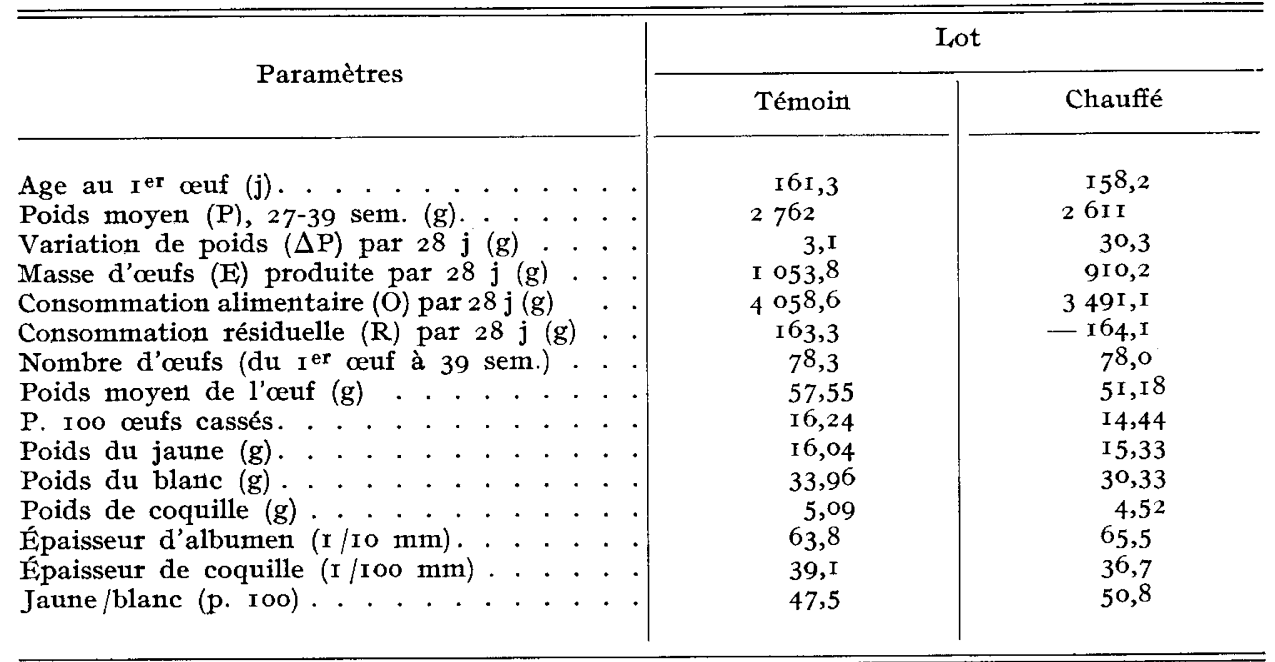

\section{TABLEAU II}

Récapitulatif des significations de l'analyse de variance à 3 voies Significances of 3-way variance analysis

\begin{tabular}{|c|c|c|c|c|c|c|}
\hline \multirow[b]{2}{*}{ Paramètres } & \multicolumn{3}{|c|}{ Effets principaux } & \multicolumn{3}{|c|}{ Interactions } \\
\hline & $\begin{array}{l}\text { (I) }= \\
\text { Lot }\end{array}$ & $\begin{array}{c}(2)= \\
\text { Génotype }\end{array}$ & $\begin{array}{c}(3)= \\
\text { Famille }\end{array}$ & $(\mathbf{I}) \times(2)$ & $(\mathrm{I}) \times(3)$ & $(2) \times(3)$ \\
\hline 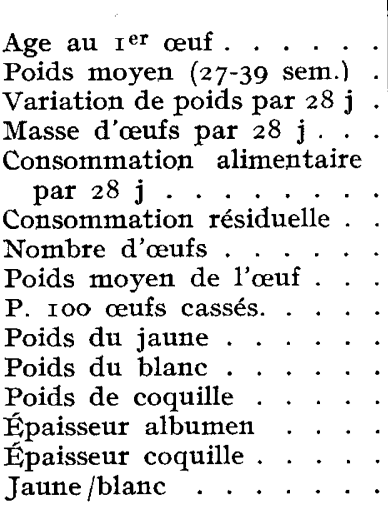 & $\begin{array}{l}(* *) \\
(* * *) \\
(* * *) \\
(* * *) \\
(* * *) \\
(* * *) \\
(* * *) \\
(* * *) \\
(* * *) \\
(* * *) \\
(* * *) \\
(* * *)\end{array}$ & $\begin{array}{c}(*) \\
(* * *) \\
(* * *) \\
(* * *) \\
(* *) \\
(* *) \\
(*) \\
(* * *)\end{array}$ & $\begin{array}{c}(* * *) \\
(* * *) \\
(*) \\
(* * *) \\
(* *) \\
(* * *) \\
\\
(*) \\
(* *) \\
(* * *) \\
(* *) \\
(* * *)\end{array}$ & $\begin{array}{c}(* * *) \\
(*) \\
(* *)\end{array}$ & $(*)$ & $(*)$ \\
\hline
\end{tabular}

(*) $\mathbf{P}<0,05$

(**) $\mathrm{P}<$ o,or.

$(* * *) \mathrm{P}<0,001$. 
positive $(r=+0,25$ sur l'ensemble du lot témoin). A partir d'une analyse de covariance, dont le détail n'est pas présenté ici, on peut, après correction pour les différences de poids corporel, évaluer la supériorité des poules $N a N a$ respectivement sur les $\mathrm{Nana}^{+}$et les $n a^{+} n a^{+}$pour le poids moyen des œufs à $2,8 \mathrm{~g}$ et 3,7 $\mathrm{g}$. L'écart de $0,9 \mathrm{~g}$ entre génotypes $\mathrm{Nana}^{+}$et $n \mathrm{a}^{+} n \mathrm{a}^{+}$est voisin du résultat obtenu par nous antérieurement (MERAT, I979).

Parmi les autres caractéristiques de l'œuf, le poids du jaune, le poids et l'épaisseur de coquille ne diffèrent pas significativement entre génotypes, mais le poids de l'albumen de l'œuf des pondeuses $N a N a$ est en moyenne plus élevé que celui de l'individu sauvage. Malgré cela, la hauteur d'albumen de 1'œuf cassé sur une surface plane est plus faible chez le mutani. Quant au rapport du poids du jaune au poids d'albumen, il est significativement plus faible chez le génotype $\mathrm{NaNa}$ en lot témoin. Enfin, quoique l'analyse de variance n'indique pas d'effet significatif du génotype sur le pourcentage d'œufs cassés, un désavantage du génotype $N a N a$ de ce point de vue est suggéré par un test $t$.

\section{Lot chauffé}

Les tableaux 6 et 7 montrent qu'en lot chauffé comme en lot témoin, l'âge au premier œuf, le nombre d'œufs pondus du premier œuf à 39 semaines d'âge, la masse d'œufs (E) et la variation de poids $(\Delta \mathrm{P})$ par 28 jours entre 27 et 39 semaines, ne diffèrent pas significativement selon le génotype au locus $N a$. Il en est de même du poids corporel moyen $(\mathrm{P})$ pendant la même période; cependant, le classement des 3 génotypes suivant ce dernier critère est inverse de celui observé en lot témoin. Parallèlement au poids, le nombre et la masse d'œufs pondus en lot chauffé montrent une légère supériorité du génotype $N a N a$ sur $n a^{+} n a^{+}$(environ $90 \mathrm{~g}$ d'œuf par poule et par 28 jours), suivi par l'hétérozygote $\mathrm{Nana}^{+}$. De plus, l'examen des périodes successives (tabl. 8) suggère une réduction de la ponte moins marquée avec le temps chez le mutant homozygote : baisse de la masse d'œufs produite de la première à la troisième période inférieure à Io $\mathrm{p}$. Ioo contre $25 \mathrm{p}$. Ioo pour l'individu $n a^{+} n a^{+}$. La consommation alimentaire $(O)$ présente le même classement, la différence entre génotypes étant cette fois hautement significative. Par contre, quoique les 3 génotypes se classent dans le même ordre pour la consommation alimentaire résiduelle (R), il n'y a pas d'écart significatif entre eux pour cette variable.

La supériorité des animaux " $\operatorname{cou} n u$ ", homozygotes surtout, pour le poids moyen des œufs est encore plus marquée qu'en lot témoin. La différence moyenne entre les génotypes $N a N a$ et $n a^{+} n a^{+}$est ici de 4,5 g. Si, par analyse de covariance, on enlève les variations liées au poids corporel, on obtient respectivement 3,9 , I,3 et 2,7 g pour estimation des différences entre les génotypes $N a N a$ et $n a^{+} n a^{+}$, $\mathrm{NaNa}$ et $\mathrm{Nana}^{+}, \mathrm{Nana}^{+}$et $n a^{+} n a^{+}$. Quant à l'influence du gène "cou nu " sur le poids des composantes de l'œuf, on observe en lot chauffé des différences hautement significatives entre les 3 génotypes pour le poids du jaune; le poids de 1'albumen ne diffère significativement qu'entre les 2 homozygotes. Le poids des coquilles, de même que leur épaisseur, varie peu en fonction du génotype. La hauteur d'albumen est plus grande pour les poules $n a^{+} n a^{+}$que pour le génotype $N a N a$, l'hétérozygote étant intermédiaire, ceci malgré le poids d'albumen supérieur pour les pondeuses " $\operatorname{cou} n u$ » et de même qu'en lot témoin. Enfin, le rapport du poids du jaune au poids du blanc est à peu près équivalent pour les 3 génotypes. 


\section{3. - Effets de la température d'élevage}

Comme nous l'avons indiqué plus haut, les lots témoin et chauffé sont éclos à 3 semaines d'intervalle et ont été placés chacun dans un local distinct, présentant de légères différences (source de lumière non identique en période d'élevage). Cependant, il est peu douteux que le régime de température qui leur a été appliqué représente la différence essentielle entre eux. On peut, selon toute vraisemblance, rapporter à la température ambiante les effets sur les différentes variables dont les valeurs moyennes figurent au tableau ro et dont la signification est donnée au tableau Ir. Nos résultats sont, pour la plupart, de même sens que ceux obtenus antérieurement. Un effet hautement significatif apparaît pour tous les caractères, à l'exception du nombre d'œufs, du pourcentage d'œufs cassés et de la hauteur d'albumen. Les effets significatifs correspondent pour la plupart à un abaissement des performances par la chaleur (poids corporel moyen, masse d'œufs et poids moyen de ceux-ci, poids des composantes de l'œuf, épaisseur de coquille), ainsi que de la consommation alimentaire globale $(\mathrm{O})$ et résiduelle $(\mathrm{R})$. De plus, le nombre moyen d'œufs par individu diminue avec l'âge en lot chauffé (tabl. 8). A cet égard, nos résultats se distinguent de ceux de EL JACK et DE REVIERS (1979). Par contre, la maturité sexuelle est un peu plus précoce en lot chauffé, conformément au résultat de PETERSEN et HORST (I978) et à l'opposé de BoONE et al. (I977). Il faut rappeler qu'une température élevée était maintenue depuis l'éclosion dans notre expérience, ce qui n'est pas le cas dans beaucoup de travaux antérieurs.

L'effet dépressif des températures ambiantes élevées sur le poids moyen des œufs est particulièrement important : $6,4 \mathrm{~g}$, soit II $\mathrm{p}$. Ioo, si l'on considère l'ensemble des génotypes. La réduction des divers composants n'est pas proportionnelle, le jaune étant le moins fortement réduit. Le rapport du poids du jaune au poids du blanc, en conséquence, est plus élevé en lot chauffé.

La réduction moyenne d'ingestion alimentaire à température élevée est, pour l'ensemble des génotypes, de l'ordre de I4 p. roo. La consommation résiduelle $\mathrm{R}$ subit également une forte in fluence de la température ambiante, reflétant une meilleure efficacité alimentaire en lot chauffé, comme l'ont observé la plupart des auteurs. Cependant, si l'on considère le rapport de la quantité d'aliment ingéré $(\mathrm{O})$ à la quantité d'œufs produite $(\mathrm{E})$, 1'efficacité alimentaire paraît se détériorer en lot chauffé chez les génotypes $\mathrm{Nana}^{+}$et $n a^{+} n a^{+}$, mais, en fait, ce critère ne tient pas compte du gain de poids appréciable dans le cas présent.

\section{4. - Comparaison des génotypes dans les deux lots: effets dépendants ou indépendants de la température}

Nous ne commenterons pas en détail la présence de différences hautement significatives entre familles pour la majorité des variables, l'interaction entre les facteurs famille et lot pour quelques-unes d'entre elles, enfin l'interaction génotype $\times$ famille pour le nombre total d'œufs pondus, l'interprétation de cette dernière n'apparaissant d'ailleurs pas clairement.

Par contre, pour certaines variables, le regroupement des deux lots permet une mise en évidence plus nette de l'influence du génotype; dans d'autres cas, 
l'analyse de variance indique une interaction génotype $\times$ température hautement significative. C'est le cas pour le poids corporel moyen (P), le poids moyen de l'œuf, le rapport du poids du jaune au poids du blanc, la consommation alimentaire.

\section{Poids vif et sa variation}

Les variations de poids vif dans chaque lot suivant le génotype sont commentées plus en détail dans un autre article (Monnér et al., I980). I1 suffit ici de rappeler que, jusqu'à ro semaines, les génotypes $\mathrm{NaNa}$ et $\mathrm{Nana}^{+}$ont été moins sensibles à l'effet dépressif de la chaleur sur la croissance que 1'homozygote sauvage (MONNE'T et al., I979). De Io à 27 semaines, le même effet dépressif moyen et la même différence de sensibilité entre génotypes s'observent en lot chauffé, alors que c'est vraisemblablement le froid relatif subi en lot témoin qui a eu un effet retardateur sur la croissance des poulettes "cou nu ". D'autre part, en lot témoin, après 27 semaines, le poids corporel est relativement stable dans les 3 génotypes, mais il croît encore sensiblement en lot chauffé. Dans ces conditions, l'absence d'effet significatif lié au locus $N a$ sur l'ensemble des deux lots réunis, en ce qui concerne le poids corporel, reflète seulement des effets contraires dans les deux lots.

\section{Performances de ponte}

Les tests n'indiquent pas d'influence du gène "cou $n u$ " sur la précocité sexuelle, le nombre total d'œufs et la masse d'œufs produite au cours de la période de contrôle, sur les deux lots regroupés comme à l'intérieur de chacun. Il reste le fait noté plus haut qu'en lot chauffé les porteurs du gène $N a$ ont en moyenne une production plus élevée que celle des animaux normalement emplumés, et l'évolution avec l'âge reflétée par le tableau 8, suggérant que 1'homozygote mutant réagit mieux à une chaleur ambiante prolongée.

\section{Poids moyen de l'auf et de ses composantes; qualité interne}

La réaction des pondeuses vis-à-vis de la chaleur varie quelque peu avec le génotype en ce qui concerne le poids moyen des œufs : la réduction de ce dernier est d'environ ro p. Ioo chez les individus porteurs du gêne $N a$ et de I4 p. roo chez la poule normalement emplumée. Cependant, l'analyse de l'ensemble des résultats montre que le gène " $\operatorname{cou} n u$ " est associé à la production d'œufs de poids moyen plus élevé, indépendamment de la température ambiante : comme nous l'avons noté précédemment, cet effet, une fois enlevée l'influence du poids corporel, devient voisin dans les deux lots : l'interaction génotype $\times$ lot pour le poids de 1'œuf, significative au seuil 5 p. roo, est essentiellement une conséquence de l'interaction correspondante qui existe pour le poids de l'animal. En ce qui concerne les composantes de l'œuf, l'influence modératrice du gène "cou nu" sur les effets d'une température élevée est plus importante chez le porteur homozygote pour le poids du jaune. Celui-ci ne varie pas en moyenne entre les deux lots (chauffé et témoin) pour les pondeuses $N a N a$. Rappelons qu'en lot témoin, on n'observe pas de différence significative entre génotypes pour ce critère, à la différence du lot chauffé. 
Quant à la sécrétion de l'albumen, le gène $\mathrm{Na}$ a sur elle, comme sur l'œuf entier, un effet d'accroissement, quelle que soit la température ambiante. L'effet général sur le poids de coquille paraît lié à celui noté sur les autres composants; le pourcentage de coquille, lui, varie peu entre lots et entre génotypes.

Pour la hauteur de l'albumen, apparaissent dans l'ensemble des différences hautement significatives entre les individus porteurs du gène "cou $n u$ " et l'individu normalement emplumé. Ce dernier a une hauteur d'albumen plus grande dans les deux lots, malgré la quantité moindre de ce composant qu'il sécrète. Le gène $N a$ semble ainsi associé à la production d'albumen plus fluide.

Nos données suggèrent d'autre part une augmentation du nombre d'œufs à coquille anormale en lot chatuffé, de même que ITo et al. (I97I) et ARIMA et al. $(\mathrm{I} 976)$; mais cette augmentation paraît différer selon le génotype. Le pourcentage de poules ayant pondu au moins un œuf mou augmente légèrement (non significativement) du lot témoin au lot chauffé pour les génotypes $\mathrm{Nana}^{+}$et $n \mathrm{a}^{+} n \mathrm{a}^{+}$, mais diminue significativement pour l'homozygote $N a N a$ qui, par ailleurs, produit plus d'œufs mous en lot témoin que les autres génotypes (tabl. I2).

\section{TABLEAU I2}

Pourcentage de poules ayant pondu au moins un ouf mou

Percentage of hens giving at least one soft-shelled or shelless egg

\begin{tabular}{|c|c|c|c|c|}
\hline & $\mathrm{NaNa}$ & Nana ${ }^{+}$ & $\mathrm{na}^{+} \mathrm{na}^{+}$ & $\begin{array}{l}\text { Différences } \\
\text { entre génotypes } \\
\text { intralot }\end{array}$ \\
\hline Lot témoin . . . . . . . . & 44,4 & I 8,4 & I 9,4 & $\mathbf{P}<0,05$ \\
\hline Lot chauffé . . . . . . . . & 21,6 & 20,5 & $28, \mathrm{r}$ & N.S. \\
\hline 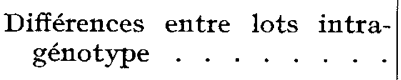 & $\mathbf{P}<0,05$ & N.S. & N.S. & \\
\hline
\end{tabular}

Nos observations relatives aux œufs cassés mettent en évidence des variations analogues aux précédentes : du lot témoin au lot chauffé, le pourcentage d'œufs cassés passe de I4,5 à I5,5 chez 1'homozygote récessif, et de II,7 à I4,6 chez 1'hétérozygote. Chez le mutant homozygote "cou nu ", au contraire, il baisse de 23,4 à 12,9 p. Ioo.

\section{Température ambiante, génotype au locus $\mathrm{Na}$ et utilisation de l'aliment}

Les différences entre génotypes pour la consommation alimentaire sont très hautement significatives dans l'ensemble et de même sens quelle que soit la température. Pour la consommation brute $(\mathrm{O})$, la différence avoisine $9 \mathrm{p}$. Ioo entre les deux homozygotes dans les deux lots. Entre l'hétérozygote et l'individu sauvage, elle est de $2,3 \mathrm{p}$. Ioo (non significatif) en lot témoin, 5,4 p. Ioo en lot chauffé. 
Pour la consommation résiduelle (R), $N a N a$ a une surconsommation de près de $22 \mathrm{~g}$ ( 6 $6 \mathrm{p}$. IOo)/individu/jour par rapport à $n a^{+} n a^{+}$en lot témoin, mais en lot chauffé cette surconsommation s'abaisse à $2,6 \mathrm{~g} /$ poule/jour et n'est plus sîgnificative. Entre $\mathrm{Nana}^{+}$et $n a^{+} n a^{+}$, les valeurs correspondantes sont $6,3 \mathrm{~g}$ en lot témoin et $\mathrm{I}, 7 \mathrm{~g}$ en lot chauffé. En termes d'indice de consommation (grammes d'aliment consonmé pour I g d'œuf produit), les valeurs des génotypes $N a N a$, $\mathrm{Nana}^{+}$et $n \mathrm{a}^{+} n \mathrm{a}^{+}$sont respectivement en lot témoin 4,07, 3,70 et 3,77 et en lot chauffé $3,82,3,86$ et 3,83 .

L'efficacité alimentaire en lot témoin est évidemment moins bonne pour le mutant $(\mathrm{NaNa})$ que pour l'individu normalement emplumé, mais en lot chauffé elle est à peu près équivalente pour les deux homozygotes. La poule hétérozygote est intermédiaire pour ce critère.

Ces variations associées à la mutation $N a$ peuvent être en rapport avec la barrière thermique isolante du plumage : disposant d'une moins bonne couverture de plumage, le mutant consomme plus que l'individu normalement emplumé, à poids, variation de poids et production égaux à température ambiante modérée ou froide, afin de maintenir sa température corporelle. On peut rapprocher cette interprétation de l'observation par TouchBuRN et BLUM (I972) d'une dépense énergétique accrue des poussins " $\operatorname{cou} n u$ " dans un local peu chauffé. A température élevée, la pondeuse normalement emplumée est en hyperthermie chronique : elle doit ingérer moins d'aliment afin de réduire sa charge énergétique et maintenir sa température corporelle à un niveau convenable, mais cette ingestion alimentaire peut ne plus suffire au maintien de la production d'œufs au niveau du lot témoin. Ce handicap est moindre pour le mutant. Quant à l'hétérozygote, il apparaît, ici encore, intermédiaire : en lot témoin, il a une moins mauvaise efficacité que l'homozygote dominant; en lot chauffé, il est moins défavorisé que l'homozygote récessif. La réduction de l'ingéré en lot chauffé paraît un peu plus faible que celle des deux homozygotes.

\section{Conclusions}

L'élevage en milieu chaud se traduit par la réduction de la consommation alimentaire et de la vitesse de croissance, et par une diminution des performances de ponte lorsque la chaleur ambiante est maintenue assez longtemps après l'entrée en ponte.

Faisant suite aux résultats sur jeunes (MONNET et al., I979), les présentes observations montrent que le gène "cou nu ", en plus d'un effet favorable à la croissance en ambiance chaude, permet, en présence d'un stress thermique de longue durée, une meilleure persistance de la ponte et la formation d'œufs de plus grande taille. Les individus hétérozygotes ont, en moyenne, des caractéristiques intermédiaires pour la plupart des paramètres étudiés : en lot témoin, ils sont moins gênés par les faibles températures que l'homozygote "cou nu "; en ambiance chauffée, ils sont moins désavantagés que l'individu normalement emplumé.

L'hypothèse la plus plausible pour expliquer la plupart de nos observations semble liée à l'effet du gène $N a$ sur le plumage et par voie de conséquence sur les pertes caloriques vers le milieu environnant. Nos observations ne permettent qu'une constatation indirecte de l'effet du gène " cou nu " sur le métabolisme énergétique de la poule adulte : une étude calorimétrique pourrait préciser les 
limites de température convenables pour un optimum de production des individus porteurs du gène $\mathrm{Na}$.

Les effets associés à ce gène sur le poids de l'œuf et sa qualité interne, par contre, n'apparaissent pas liés de façon évidente à l'effet sur le plumage. Il est à rappeler que des données sur le poids de l'œuf ont été présentées aut moins pour deux autres gènes supprimant ou diminuant le pouvoir isolant du plumage : sc (scaleless) par AввотT et Asmundson (I962) et l'allèle $K^{n}$ au locus $K$ lié au sexe (Somes, I970, I975). Dans les 2 cas, une augmentation de plusieurs grammes du poids moyen des œufs est associée au génotype mutant, sans accroissement parallèle du poids corporel.

Il est prématuré, bien entendu, de conclure quant à une utilisation pratique éventuelle du gène $N a$ pour la production d'œufs en climat chaud. De nombreuses questions sont posées, notamment sur les limites de température, et peut-être d'hygrométrie, dans lesquelles il peut être avantageux, la présente étude comportant en particulier une température élevée constante, sans fluctuations importantes. Une connaissance plus précise des besoins alimentaires d'entretien et de production des poules "cou nu" permettra aussi un ajustement éventuel de 1a formulation de 1'aliment aux dépenses de l'animal. On peut aussi rappeler que la présente étude est faite à partir de reproducteurs d'un type relativement lourd et ne peut être transposée sans vérification à des souches plus légères de type "ponte ". Cependant, nos résultats suggèrent l'intérêt de recherches ultérieures visant à déterminer les conditions et les limites d'une utilisation éventuelle du gène $N a$ en aviculture tropicale. Le gène "cou $n u$ ", dominant simple avec identification aisée de l'hétérozygote, peut être fixé facilement dans une lignée de reproducteurs destinés à un croisement terminal pour la production de descendants hétérozygotes.

Reçu pour publication en janvier 1981 .

\section{Remerciements}

Nous remercions le Dr J. C. BLUM, Station de Recherches avicoles, I.N.R.A., 37, Monnaie, de ses remarques et suggestions concernant ce manuscrit.

\section{Summary}

Naked neck gene, laying performance and food efficiency according to temperature in the fowl

\footnotetext{
Females ef the three genotypes $\mathrm{NaNa}$ (naked neck homozygotes), $\mathrm{Nana}^{+}$(naked neck heterozygotes) and $n a^{+} n a^{+}$(normal plumage) were hatched from the same parents and distributed in two groups, each coming from a distinct hatch: " control " (kept at moderate temperature, with fluctuations according to climatic variations) and "heated" (constant $3{ }^{\circ}{ }^{\circ} \mathrm{C}$ from 4 to 39 weeks of age). Laying performances together with food intake were measured from 27 to 39 weeks of age. In the control, homozygous naked neck females had an adult body weight considerably inferior (by about $300 \mathrm{~g}$ ) to that of hens with normal plumage, although they consumed about 4 oo $\mathrm{g}$ more per 28 days and their mean egg weight was superior by $2.5 \mathrm{~g}$. They had more broken eggs; their eggs contained about the same quantity of yolk but had more albumen, this albumen being less consistent than for normal hens. There were more softshelled or shelless eggs among $\mathrm{NaNa}$ females. Heterozygotes in general were intermediate for
} 
these traits, but they were closer to the $n a^{+n} a^{+}$genotype for food consum tion, mean egg weight and yolk/albumen ratio, and to the $N a N a$ birds for albumen height.

In the heated group, homozygous naked neck hens had a slightly (although not significantly) heavier body weight than homozygous normal hens; they consumed $338 \mathrm{~g}$ more food per 28 days; their mean egg weight was $4.5 \mathrm{~g}$ higher than that of $n a+n a+$ females, both yolk and albumen being heavier. As in the control group, albumen was less consistent for $N a N a$ hens. Heterozygotes were intermediate but closer to $\mathrm{NaNa}$ birds for mean egg weight and albumen consistency. Egg number was slightly higher for naked neck birds in the heated group, although not significantly.

The effect of genotype at $N a$ locus was consistent at both temperature regimens for food consumption, mean weight of the egg and its components, and albumen height; on the other hand, there was a significant or highly significant genotype $\times$ environment interaction for adult body weight, residual food consumption (corrected for body weight and egg mass), mean egg and yolk weight and yolk/albumen ratio.

\section{Références bibliographiques}

Aвbотt U. K., Asmundson V. S., I962. Response to selection under severe environmental stress. Proc. XIIth World's Poultry Congress, section papers, 30-36.

Ahmad M. M., Moreng R. E., Mulifer H. D., i 967 . Breed responses in body temperature to elevated environmental temperature and ascorbic acid. Poult. Sci., 46, 6-I 5 .

ARad Z., Moskovits E., Harder J., 1975. A preliminary study of egg production and heat tolerance in a new breed of fowl (Leghorn $\times$ Bedouin). Poult. Sci., 54, 780-783.

ARIMA Y., Mather F. B., Ahmad M. M., I976. Response of egg production and shell quality to environment temperature in two age groups of hens. Poult. Sci., 55, 818-820.

Boone M. A., Vo K. V., KNEchTGES J. F., I 977 . Effect of high temperature on sexual maturity. Poult. Sci., 56, 1347 (abstr.).

Bordas A., Merat P., Sergent D., Ricard F. H., I978. Influence du gène $\mathrm{Na}$ (" cou nu $)$ sur la consommation alimentaire, la croissance et la composition corporelle du poulet selon la température ambiante. Ann. Génét. Sél. anim., 10, 209-23r.

BXERLY T. C., I94I. Feed and other costs of producing market eggs. Univ. Maryland Agricultural Experiment Station, bulletin $n^{\circ}$ Ar.

Campos A. C., WILcox F. H., ShaffNer C. S., 1960. The influence of fast and siow changes in ambiant temperature on production traits and mortality of laying hens. Poult. Sci., 39, I I 9-I 29.

Снiма M. M., I975. Untersuchungen zum Einfluss hoher Dauertemperaturen auf Körpertemperatur, gewichtsentwicklung und Leistungsreaktion von leichten und mittelschweren Legehybriden. Thèse, Berlin.

Clark C. E., Amm H., r965. The adaptability of chickens to various temperatures. Poult. Sci., 44, I003-1009.

CRAWFORD R. D., I976. Incomplete dominance of the gene for naked neck in the domestic fow1. Poult. Sci., 55, 820-822.

DORMINEy R. W., I968. Physiological and genetic aspects of acute and chronic heat stress in the domestic fowl. Diss. abstr., B, 29, I483 B.

EI. JACK M. H., DE, REVIERS M., I 979. The influence of fluctuating high environmental temperature on egg production, fertility and hatchability of the domestic fowl. Arch. Geflügelk, 43, I39-I 43 .

Emmans G. C., I974. The effects of temperatura on the performance of laying hens. In : Energy requirements of poultry. Ed. Tr. Morris an] B. M. Freeman Br. Poult. Sci., Ediniburg.

EMERSON G., I975. Poultry: effects of extreme heat on caged layers surveyed. Feedstufs, 47 I9.

Gous R. M., BYerdy T. C., Thomas O. P., KesSlek I. W., I978. A partition equation to predict food and energy intake by laying hens. Proc. XVIth Wld. Poultry Congress, I-8.

GUIILAUME J., I976. The dwarfing gene $d w$ : its effects on anatomy, physiology, nutrition, management. Its application to poultry industry. World's Poult. Sci. J., 32, 285-304.

HILLERMAN J. P., WIISON W. O., I954. Acclimation of adult chickens to environmental temperature changes. Amer. J. Physiol., 180, 59r-595.

Horst P., PETERSEN J., I979. Der effekt des Dwarf. Genes auf das Akklimatisationsvermögen von Legehennen an hohe Umwelttemperaturen. Arch. Geflügelk., 43, 242-245. 
Huston T. M., Joiner W. P., Carmon J. L., i957. Breed differences in egg production of domestic fowl held at high environmental temperature. Poult. Sci., 36, I 247 -I 254.

HUT T F.B., 1949. Genetics of the fowl. McGraw Hill, New York.

ITO T., MORIya T., Yamamoto S., MrmURA K., I97I. Effects of environmental temperature on egg production, food intake and water consumption in laying White Leghorns. J. Fac. Fish. Anim. Husb. Hiroshima Univ., 9, I5I-I6o.

LEESON S., LEWIS D., SHRIMPTON D. H., I973. Multiple linear regression equations for the prediction of food intake in the laying fowl. Brit. Poult. Sci., 14, 595-608.

MCDONALD D., 1978. Feed intake of laying heris. World's Poult. Sci. J., 34, 209-221.

MERAT P., I979. Effets associés au gène $\mathrm{Na}$ ("cou nu") sur le poids corporel et le poids des œufs chez des poules "normales" et "naines ". Ann. Génét. Sél. anim., 11, 127-131.

Merat P., Bordas A., LEFEBVRE J., I974. Effets associés aux gènes dw (nanisme) et $N a$ (cou nu) chez la poule sur la production d'œufs et la consommation alimentaire à deux températures. Ann. Génét. Sél. anim., 6, 331-343.

Monnet L. E., Bordas A., MERAT P., r979. Gène cou nu et performances de croissance selon la température chez le poulet. Ann. Génét. Sél. anim., 11, 397-412.

MONNET L. E., BORDAS A., MERAT P., I980. Gène "cou nu ", poiđs corporel et paramètres anatomiques et physiologiques des poulettes et poules adultes selon la température. $A n n$. Génét. Sél. anim. 12, I5-31.

Payne C. G., I966a. Environmental temperature and egg production. In : Pbysiology of the fowl, pp. 235-24I, Ed. C. Horton Smith and E. C. Amoroso. Oliver and Boyd, Edimburgh, London.

Peterensen J., Chima M. M., Horst P., I976. Body temperature as a measure of acclimatization in laying hens. Zeit. Tievzuchtung Zuchtungsbiol., 93, 237-25I.

PETERSEN J., HORST P., I978. Hohe Umwelttemperaturen als auslösender Faktor von Genotyp-Umwelt Interaktionen beim Legehuhn. Arch. Geflugelk, 42, 173-1 78.

SCOTT T., CRAwFORD R. D., r977. Feather number and distribution in the throat tuft of naked neck chicks. Poult. Sci., 56, 686-688.

SelvaraJah T., I970. Studies on sex-linked dwarfism in the domestic fowl. Kajian vet., 2 , I8I-I95.

SMITH T., LEE R., I977. A study of the Naked Neck gene of the fowl. Poult. Sci., 56, I 758 (abstr.).

Smith A. J., I973. Some effects of high environmental temperatures on the productivity of laying hens (a review). Trop. Anim. Hlth Prod., 5, 259-27 I.

SMith A. J., I979. Changes in the average weight and shell thickness of eggs produced by hens exposed to high environmental temperature (a review). Trop. Anim. Hlth Prod., 6, 237-24I.

SMITH A. J., OrIver J., I97I. Some physiological effects of high environmental temperatures on the laying hen. Poult. Sci., 50, 91 2-935.

SOMES R. G. (Jr), I970. The influence of the rate of feathering allele $K^{n}$ on various quantitative traits in chickens. Poult. Sci., 49, 125 I-1256.

SOMES R. G. (Jr), I975. Pleiotropic effects of the sex-linked delayed feathering gene $K^{n}$ in the chicken. Poult. Sci., 54, 208-2 I6.

Touchburn S. P., Blum J. C., 1972. Effects of genes for dwarfism (dw) and naked ncck (Na) on chick growth and lipid metabolism. Ann. Genét. Sél. anim., 4, 31 I-316.

WILsON W. O., ITO S., Siopes T. D., I972. Production traits of Leghorn pullets in controlled temperatures. Poult. Sci., 51, roI4-1023. 